\title{
Japanese Video Games in Singapore: \\ History, Culture and Industry
}

\author{
Benjamin Ng Wai-ming* \\ Department of Japanese Studies \\ National University of Singapore
}

Globalization of Japanese popular culture is reshaping the global cultural landscape. Some forms of Japanese popular culture (such as video games animation and sushi) are well-received internationally, whereas others (such as pop music, films and TV dramas) are only popular in Asia. Of all forms of Japanese popular culture, video game is perhaps the most powerful due to its strong universal appeal. It has dominated the world market since the mid-1980s. This article uses Singapore as a case study to demonstrate the global popularization of Japanese video games.

There has been a boom of Japanese popular culture in Singapore in the 1990s. In particular, Japanese video games, comics and animation have become an integral part of youth culture in Singapore (Ng, March 2000: 234-246; Ng, May 2000: 44-56; Ng, June 2000: 1-14). Video game is a neglected topic in cultural studies. Although there are some basic studies of Japanese video games in the Western world (Hayes \& Disney, 1995; Herz, 1997; Kinder 1991; Monopolies, 1995; Sheff, 1993), its impact in Asia is largely unknown. This article is a preliminary study of the Japanese video game culture and industry in Singapore from historical and socio-cultural perspectives, focusing on consoles, games and players. Based on interviews, questionnaires and data from newspapers and magazines, this research aims at providing a general overview of the history and impact of Japanese video games in Singapore. All the data and analyses are basic and this is beyond the scope of this paper to discuss any particular issue or theory in details. This paper consists of four sections. The first three sections outline the development of home video game consoles, handheld electronic games and game arcades respectively. The concluding section pinpoints the characteristics of the video 
game culture in Singapore from a comparative perspective. It also discusses the political, social and cultural implications of Japanese video games in Singapore.

\section{Home Video Game Consoles}

In terms of market share, home video game consoles are much more important than handheld game consoles and arcade machines. When scholars and people talk about video games, they usually refer to home video game consoles.

In Singapore, arcade machines and handheld electronic games came earlier than home video game consoles. Most Singaporeans first came to know video games by playing some unsophisticated games, such as Pong, Pac-Man, Galaxian, Breakout, Asteroids, or Space Invaders, on coin-operated machines in the late 1970s or early 1980s. These games were introduced by American video game companies such as Atari and Midway, although the software was actually designed by Japanese companies like Namco and Taito. Some children also played electronic handheld games, such as Western Bar, Boxing, and Submarine, in this period.

The first home video game console, Atari 2600, was introduced to Singapore by the US video game giant, Atari (founded in 1974) in the early 1980s. Atari 2600 was the world's first successful home video game console, but it failed to create a video game revolution in Singapore as it did in the US. During this time, the home video game system was something too new to catch on even among game players in Singapore who did not find the idea of having their own video game system attractive or affordable.

The Americans opened the doors of the Singapore video game market for the Japanese to enter. It was Nintendo which created the first video game boom and a video game culture in Singapore. Nintendo came to Singapore in 1985, the same year it launched its products in the US market. It soon dominated the Singapore market with its 8-bit game console, Nintendo Entertainment System (NES, also called famicom), thanks to its excellent games such as The Mario Brothers, Donkey King and Contra. By the standards of the mid-1980s, NES was not considered very affordable. The machine was priced at around $\$ 250$ [all currency amounts in this paper are given in 
Singapore dollars] and a cartridge was about $\$ 40$. Only the well-to-do families could afford to buy an NES for their children. Hence, the video game started as a group activity. Children and classmates would get together and play video games in the house of a friend who owned an NES. Nintendo was the name of the game. During this time, it was synonymous with video games in Singapore terminology.

The popularity of NES reached its peak in the late 1980s. ${ }^{1}$ A flood of unauthorized NES-compatible machines (the so-called "red and white machine," sold at about \$120) and pirated Nintendo cartridges (about $\$ 10$, mostly made in Taiwan and Thailand) played an important role in popularizing NES. In the early 1990s, NES began to lose ground to Sega Genesis, the Sega 16-bit game console.

Sega was the archrival of Nintendo in the late 1980s and early 1990s. Sega Master System lost the battle to Nintendo NES in the 8-bit game console market, but turned the table in 1989 by introducing the first 16-bit game console in Singapore, Sega Genesis. It was a huge success, because Singapore players were already tired of the 8-bit games. 16-bit technology made much better graphics and colors. Nintendo was slow to develop its 16-bit game console which did not enter the Singapore market until 1991. Hence, from 1989 to 1991, it was the golden age of Sega in Singapore when Sega Genesis captured about $50 \%$ of the video game market share. It introduced some popular games such as Sonic the Hedgehog, Super Shinobi, Herzog Zewei, and Rambo.

Nintendo made an impressive comeback in 1991 by launching the long-awaited 16bit game console, the Super Nintendo Entertainment System (SNES, also called Super Famicom) which was even better than Sega Genesis both in graphics, sound and software. SNES conquered the lion's share of the video game market in Singapore in just a few months. SNES included many good games designed by Nintendo or released exclusively for SNES, such as Final Fantasy (versions 4, 5 and 6), Super Mario World, Live a Life, Chrono Trigger, Romancing Saga and Dragon Quest (versions 4 and 5). SNES was the most successful product that Nintendo ever made. It dominated the market for about five years and only gave way to 32-bit game consoles made by Sony (Sony Playstation) and Sega (Sega Saturn) in 1996. Ironically, over and above its 
superb technology and excellent games, the availability of pirated hardware (the socalled "Super UFO") and software also boosted its sales.

Both Sony Playstation and Sega Saturn came to Singapore by the end of 1994. They used CDs instead of cartridges, providing a completely different level of graphics and sound effects. The graphics are 3D and the sound is stereo, providing near arcadequality games for home entertainment. Sony Playstation was fast to catch up and became the biggest winner in the history of the video game industry in Singapore. Basically all the top software companies developed games for Playstation. Popular games for Playstation include the Tekken series, Ridge Racer series, Parasite Eve and Time Crisis. In 1998, Sony organized a Tekken competition at Takashimaya, the largest department store and shopping complex in Singapore. In December 1998, Namco held a Ridge Racer $4 R$ Type competition at Takashimaya as an important event in the Playstation Game Show 1998 (Sony, 1999: 3-4). In 1998, Sony Playstation fans in Singapore set up a popular web site called Singapore Playstation Page to exchange information. Sony Playstation has been the number one game console in Singapore since 1996 and it seems that it will continue its dominance beyond the year 2000 . According to our March 1999 survey on 300 young Singaporeans between 13 and 29, $34 \%$ of our respondents are owners of Sony Playstation and 15\% are owners of Sega Saturn.

Why has Sony Playstation been so successful in Singapore? Mr. Maruse Katsuhiko, the manager of Asia Project Department at the Sony Playstation Office in Singapore (the official name is Sony Computer Entertainment Inc. Singapore Representative Office for Singapore and Malaysia), during an interview on 10 October 1998, told us with chagrin that the most decisive factor is the availability of cheap pirated CD software. In Singapore, almost all Playstation consoles can be modified to use pirated CD software by inserting a special chip. Game retailers do the modification for about $\$ 50$. A pirated CD costs as low as $\$ 3$, about $20-30$ times cheaper than the original. Most of the pirated CDs were imported from Malaysia, but some came from Taiwan, China, Hong Kong or Thailand. Sony Playstation also has the largest number 
of games, and hundreds of them have pirated editions. The other reason is that Sony put more emphasis on the Southeast Asian market than Sega. A regional office was set up in Singapore in December 1996 to promote and monitor the sales of Sony Playstation in Singapore. It provides repair services for its Sony Playstation consoles. It even made Sony Playstation consoles specifically for Asian nations and games for English speaking nations. For instance, its machine sold in Singapore use 200-220 voltage instead of 100110 voltage and they come with an English manual. Its games use English instead of Japanese for instruction. Sony selects software for promotion in Taiwan, Hong Kong, Singapore and Malaysia (Iwabuchi, 1999: 185-196; Robertson, 1995: 25-44). ${ }^{2}$ It has established a national distribution network in Singapore by choosing about a hundred retailers as its authorized agents. It has also authorized department stores (e.g., Takashimaya and Isetan), electric appliance shops (e.g., Best and Electric City), and game shops (e.g., Toys "R" Us) to sell its Playstation products. In order to promote Sony Playstation in Singapore, Sony Playstation office publishes a monthly newsletter in both English and Japanese, GAX (Gamers' Action Times), distributed to players free of charge through its authorized dealers in Singapore. It reports on new games, game shows in Japan and Singapore, introduces its Singapore authorized dealers, and answers questions from Singapore game players.

Sega Saturn has been the distant second. Despite its initial success, it has fallen behind Sony Playstation. One reason is that the pirated CD software for Sega Saturn is fewer in number and higher in price. Unlike Sony Playstation, Sega has not established a good marketing network. Its products can only be found in video game shops. By mid-1999, Sega stopped the production of Sega Saturn.

Sega seems to be making a comeback by launching its 128-bit game console, Dreamcast (DC) in Singapore, Hong Kong and some other Asian nations in November 1998. Dreamcast represents a breakthrough in video game technology. Not only does it offer superb graphics and sound, it also has the build-in internet capability and some useful functions such as the ability for four players to play together. It uses Yamaha sound chips which makes it a good CD player. Dreamcast has been met with 
overwhelming response in Japan, Taiwan and Hong Kong. However, the reception of Dreamcast has been lukewarm in Singapore due to high price and limited software.

Nintendo, the former champion in the Singapore market, has dropped to a pathetic third place. Its market share in home video game consoles is now insignificant. After SNES, Nintendo moved directly to develop the 64-bit game console. As a result, it left the lucrative 32-bit game console market entirely to Sony and Sega. It took Nintendo five years to introduce its 64-bit game console, Nintendo 64, to Singapore. Nintendo 64 has excellent graphics, requires no loading time, provides CD-quality sound, and has the capability for four persons to play at the same time. Unfortunately, Nintendo 64 was launched at the worst possible time. It came to Singapore in June 1996 when most Singaporeans had just bought their first Sony Playstation or Sega Saturn. They had not yet digested the 32-bit technology and were not interested in investing in 64-bit game consoles. Nintendo also made a terrible mistake in designing and marketing Nintendo 64. The adoption of the cartridge format and the price of its software (about $\$ 100$ each) also hurt its sales. Its games are generally very good (e.g., Pikachu and Legend of Zelda 64), but the titles of software for Nintendo 64 are still small. Some top game developers, such as Square and Capcom, refused to create games for Nintendo 64. Although it is a moderate success in Japan, Taiwan and Hong Kong, Nintendo 64 is a business fiasco in Singapore. Only 2 out of 100 respondents in our January 1998 survey owned a Nintendo 64. Even a pirated console (Taiwan-made Doctor V64, at \$700) that arrived Singapore in early 1998 cannot save it because it is too expensive and inconvenient. The price of Nintendo 64 was dropped from $\$ 500$ to $\$ 250$ in order to be competitive with Sony Playstation and Sega Saturn. Local players, however, still shy away because its software is too expensive. Now, Sega Dreamcast has entered the competition. Nintendo 64 will have an uphill battle ahead.

Who will be the leader of the video game market in Singapore as well as the world in the future? Dreamcast and Nintendo 64 are now leading the technology and their future will depend on the price and the quality of their software. Sony, the current leader, launched its next generation Playstation, Playstation 2 in Japan in early 2000. It 
uses DVD-Rom, has internet capability, and can play CDs for Sony Playstation. Playstation 2 was an overwhelming success in Japan. It will be introduced to Singapore and the rest of the world in late 2000 or 2001 and will be a strong candidate to be the future's leader. Undoubtedly the major competitors will be all Japanese and the dominance of Japanese video games will continue for many years to come. ${ }^{3}$

\section{Handheld Electronic Games}

Pocket-size electronic games have been in Singapore for a long time. In the late 1970s and early 1980s, most of the games were very simple and the players were mostly primary and secondary school students. In the 1990s, handheld electronic games became more popular, the games more sophisticated, and the players more diversified.

Before the 1990s, the handheld electronic game market was wide open to minor toy and electronic companies. Small factories in Taiwan, China, Hong Kong, Malaysia and Korea made a lot of handheld electronic games. They were so cheap (usually less than \$10) that children could buy them out of their own pockets. Games were very simple, and thus had no appeal to adults. Each unit was programmed only to play one game. Even kids could master the game in a few days and they quickly got bored. Casio also incorporated games such as car race and shooting into some of its digital watches. Tetris (about \$12) created the first handheld electronic game fever in Singapore in the late 1980s. Some calculators could also play Tetris. Nintendo was perhaps the only major Japanese manufacturer that made an impact on handheld electronic games in the 1980s. Its first generation non-cartridge electronic game device, Game and Watch, was quite popular in the late 1980s.

Big names such as Sega, Sony, and Bandai, have finally entered this lucrative market in Singapore in the 1990s. Hand-held electronic games have become a popular toy and a form of entertainment for both children and adults. However, in terms of the market share in video games in Singapore, they are not as important as home video game consoles. 
Game Boy and Game Gear are the first generation of cartridge-based handheld game consoles. Nintendo is the leader in this area and its Game Boy is the most successful handheld console ever made in the history of video games. It beat Sega Game Gear in Singapore and many other nations. According to our March 1999 survey, $17 \%$ of our respondents own a Game Boy, but only $2.3 \%$ own a Game Gear. Nintendo launched its Game Boy in Singapore in 1989 and it was a business success. It could play many popular Nintendo games, such as Tetris, Arkanoids, The Mario Brothers, and Donkey King. It has dominated the handheld game console market since 1989 and is still the leading handheld game console system in Singapore.

Sega was a late comer which introduced its Game Gear $(\$ 100)$ in Singapore only in 1991, posing a big challenge to Game Boy in the early 1990s. Unlike the monochrome Game Boy, Game Gear has a color LCD screen. It has adopted some Sega hot games such as Sonic the Hedgehog. It did not overtake Game Boy mainly because little pirated software for Game Gear appeared.

Nintendo strengthened its position in the Singapore market by launching the second generation Game Boy in 1994 and the third generation Game Boy in 1997. The second generation Game Boy has a better body design, and the third generation Game Boy can be played in darkness. The price of Game Boy (generations 1-3) in Singapore also dropped from $\$ 100$ in the early 1990 s to about $\$ 70$ in the late 1990 s. The success of Game Boy, ironically, is also due to the availability of cheap pirated cartridges. Most of these pirated cartridges are made in Taiwan. Each carries 10-30 games, but only costs the price of an original cartridge. In 1995, Pokemon, a game software for Game Boy, was created. It became a smash hit in Japan in 1997. Its spin-off software, Pikachu, was made into a game for Nintendo 64 in 1998 and a popular handheld electronic game, Pocket Pikachu. However, Pokemon did not create a craze among Game Boy fans in Singapore. Game shops in Singapore usually recommend Taiwanmade 30 in 1 pirated cartridges rather than original software like Pokemon for getting a higher profit. In early 1998, Game Boy Pocket (\$70) was introduced to Singapore. Its functions are the same as Game Boy but it is pocket-size. In October 1998, Nintendo 
launched the fourth generation Game Boy, Game Boy Color. It has a very attractive body design and can play some sophisticated games on its color LCD screen. Game Boy Color is a hot product in Japan and Hong Kong, but the initial response in Singapore is lukewarm. The price is $\$ 140$ which is considered a bit expensive. There is not much pirated software for Game Boy Color. A strange phenomenon is that most Game Boy Color players in Singapore do not buy software designed for Game Boy Color and are still playing with their old pirated cartridges initially assigned for older versions of Game Boy. This is a waste because the best features of Game Boy Color can only be demonstrated by using new and original software.

Sega Game Gear is losing its competitive edge. It failed to improve much in quality and price. Game Gear has very few pirated cartridges in Singapore and the console costs about $\$ 120$. Nowadays, very few people buy Game Gear.

Besides Game Boy and Game Gear, three new competitors have entered the handheld game console market in Singapore-Sony Pocket Station, Bandai Wonder Swan and SNK Neo Geo Pocket. All of them use cartridges or cards. They are popular in Japan, Hong Kong, and Taiwan, but have drawn little attention in Singapore so far.

While Nintendo has secured its dominance in the cartridge-based handheld game console market, the old-style non-cartridge handheld electronic games have made a strong comeback, thanks to the phenomenal but short-lived worldwide Tamagotchi fever.

Tamagotchi is an electronic virtual pet housed in an egg-shaped and egg-size console, and is produced by Bandai, a Japanese toy and video game software company. Invented in 1996, Tamagotchi created a great commotion among high school girls in Japan and soon became a national and then international craze. Before it came to Singapore in April 1997, it had already created a fever in many cities such as New York and Hong Kong. ${ }^{4}$ It was an instant success in Singapore and for a time, Tamagotchi became the talk of the town. When Takashimaya declared its plan to sell this electronic pet on 8 April 1997, hundreds of people, including some Japanese but mostly Singaporeans, queued up outside and bought up the entire stock of 1,000 pieces in less 
than two hours. Toys "R" Us had a similar reaction. Any shop that could import Tamagotchi was a big winner. All Tamagotchi sold during this time were Japanese versions imported from Japan. Buyers had to read the Japanese manual to learn how to take care of it (The Straits Times, 9 April 1997: 8). More than ten imitations, including cat, dog, monster, frog and dinosaur, also came to Singapore. They were made in Japan, Taiwan, Hong Kong or China. A Hong Kong-made imitation, Tamahonam, which is a game of training a gangster by teaching him to drink, smoke and fight, was banned in Singapore.

Tamagotchi soon became a national craze in Singapore, which lasted for about six months. Both students and adults were crazy about it, some playing it day and night. Bandai launched a number of Tamagotchi products in Singapore, such as key chains, lunch boxes, stationary, books, T-shirts, and socks. Tamagotchi was adapted into a Nintendo Game Boy game and a Sony Playstation software. The mass media picked up stories about it. Some schools, offices and factories banned it. A woman was fired because she hid in the toilet to play with her Tamagotchi. A female driver had a car accident because she played with one while driving. Some Singaporeans set up cyber graveyards for their deceased electronic pets. Many people were quick to take advantage of this fad. For instance, New Paper, a Singapore tabloid, set up a column. For a fee, one could place an obituary for one's dead electronic pet. Even the Singapore government made use of this fad, introducing in 1997 the "Tamagotchi War Hero," an educational software using a virtual animal to teach Singapore history at school. The fad was over in a few months, and all of a sudden no one was interested in it anymore. Many shops did not know what to do with their stocks. The price went through a free fall. Although Bandai introduced an English version of Tamagotchi to Singapore and Asia in 1998, no one was interested. In 1998, it reached its bottom price at $\$ 5$. Tamagotchi was game over.

When people were tired of Tamagotchi, a new sensational product, Digimon (digital monster) was created in Japan in 1997. It was one of the spin-offs of Tamagotchi developed by the Tamagotchi team at Bandai (International Herald Tribune, 
1997: 6). Digimon is also an electronic virtual pet, but it is more sophisticated than Tamagotchi. The player cultivates the virtual pet into a monster which can fight with another monster when two consoles are linked. The winning monster increases its strength and a powerful Digimon has a high resale value. Unlike Tamagotchi, Digimon is only popular among small children, particularly primary school pupils in Singapore.

Digimon was introduced to Singapore in February 1998. During the first six months, more than 300,000 were sold. In September 1998, the second generation Digimon arrived. More than a thousand people waited outside Takashimaya for its opening. The third generation came in November 1998. At a promotion sale held in Great World City by the Digimon authorized distributor in Singapore, Rubberband, more than 10,000 were sold in a few hours. In December 1998, the fourth, fifth, sixth and seventh generations of Digimon were introduced by parallel importers. ${ }^{5}$ The eighth, ninth and tenth generations came in late 1999 and early 2000.

Now even Seven Eleven carries this hot item. A China-made imitation, Battle Beast, and a Hong Kong imitation, Digi Fighter, are sold at \$10 in Singapore since late 1998. It seems that more imitations of Digimon are on the way to Singapore. Digimon has also become a video game for home consoles and a virtual pet that computer users can fight with others on the internet.

Compared with Tamagotchi, Digimon is relatively expensive because of the prevalence of parallel import. The size of all Digimon is small $(4 \times 6 \mathrm{~cm})$. Versions 610 are called pendulum and they cannot link with older versions. In 1999, Bandai finally launched pendulum (versions 6 and 7) of Digimon in Singapore, bypassing versions 4 and 5. The Bandai office in Singapore showed a 10-second TV commercial to promote Digimon in Singapore in early 1999 and mid 2000.

Digimon has been banned by some schools in Singapore because it makes noises and promotes a fighting spirit. One school even suggested the following tips for parents to help cope with this problem:

(1) only allow the children to play with it after they finish their homework.

(2) only allow the children to play for up to two hours a day. 
(3) encourage children to do other more meaningful things, such as reading and chess.

(4) do not overreact. This is after all a fad and it will die down soon (Lianhe wanbao, 1 December 1998: 11).

The craze has not died down in Singapore yet. On the contrary, it seems that it has not yet reached its peak. Digimon was the most popular handheld video game in Japan in 1998 and 1999. It was adapted in comics and incorporated into a Playstation game and a Wonder Swan game. It is also very popular in Hong Kong, Taiwan, the US and the UK.

Recently, it has become common for Digimon players to gather at public places like subway stations (the hottest is Orchard station), parks, shopping malls, and game centers to have their Digimon fight against each other. Taking advantage of this craze, some organizations including community centers, churches, and voluntary organizations begin to include Digimon in their activities. For instance, the Kowloon Club, an organization for Hong Kong immigrants in Singapore, organized a Digimon competition on 20 March 1999 (Kowloon Club, Newsletter, 1999: 6). Rubberband held a large-scale Digimon competition on 30 September 2000. As the fad gains momentum, not only children, but young adults as well are getting interested in it. Singaporeans have set up many websites on Digimon to exchange tips on how to win.

Besides Tamagotchi and Digimon, there are usually about 50-100 different kinds of non-cartridge based handheld electronic games made by Japanese, American, Chinese or Taiwanese companies available on the market. The prices range from $\$ 5$ to $\$ 25$. Some are simple but ever popular games such as Black Jack and Chess, while others are simplified adaptations of popular video games such as Tetris, Bomberman, Crazy Climber, The Mario Brothers, Defender, Bowling, Soccer 98, and Breakout. Their size is getting smaller and many can be used as key-chains. Most electronic games in this category are not very popular and they come and go in the Singapore market.

\section{Game Arcades}


In Singapore, playing video games at game arcades is a popular form of entertainment. According to the Public Entertainment Licensing Unit of the Singapore Police Force, there are 144 video game centers in Singapore. Many are chain centers that belong to big companies, such as Super Funworld, Funland, Funworld, Wywy Wonderspace and Fun Factory. Super Funworld has 12 game centers, Funland has 10, Funworld has nine, Wywy Wonderspace and Fun Factory have seven (Singtel, 1998: 92-93; Singtel, 1999: 82). The Singapore government sets the following four basic guidelines for video game centers:

(1) video game centers should be located in shopping, recreational or commercial centers.

(2) The minimum size of a video game center should be at least 120 sq. meters. Video game machines should not occupy more than $50 \%$ of the total floor space. Besides video game machines, the remaining floor space must be used to include non-video amusement games like simulators, table soccer and a children's corner containing rides and games for children.

(3) The maximum operating hours of a video game center is until midnight.

(4) All games must contain a high element of skill, and they should not encourage gambling or violence. Video game machines must be approved by the Films and Publications Department. ${ }^{6}$

Other regulations, written or unwritten, include no smoking (penalty $\$ 1,000$ ), no gambling and some basic dress codes. Students under 16 are not allowed to enter on school days before $6 \mathrm{pm}$. Students in school uniform are prohibited to enter anytime. All of these regulations make game centers in Singapore very different from their counterparts in Taiwan and Hong Kong.

In Taiwan and Hong Kong, game centers are either very small or very large. The majority are small centers with less than 50 coin-operated machines. They are usually smoky, dirty and dim. Associated with drug trafficking and gang activities, they become a target of regular raids by the police and criticism by teachers, social critics and parents. 
Game centers in Singapore have a much better image. They are clean, bright, smokeless, spacious and lively, and are accepted by the public as entertainment centers for families and friends. The majority of game arcades are located in shopping malls or department stores which can provide the huge space required by the government. Basically each shopping mall has at least one game arcade. Most machines are coinoperated, but some use tokens or stored-value tickets. Many young people go there to play, including lovers, students, and groups of friends. Players are usually in the late teens and early twenties, and are being relatively well-dressed and good-mannered. The age of the players tend to be younger at game centers outside the city. During the weekend, many children in their early teens play at game centers. At game centers in the city and weekdays, the majority of players are teenagers and young adults. The ratio between males and females is about 7: 3. The number of customers visiting game centers in weekends and holidays are about ten times more than weekdays. ${ }^{7}$

Parents also take their kids to play non-video amusement games. However, nonvideo games for kids are not very profitable and occupy a huge space. Without government's regulations, most game centers would have not introduced these games. Many big game centers also have photo-sticker machines (purikura in Japanese) made by video game makers such as SNK, Sega, and Namco. ${ }^{8}$ Therefore, video game centers in Singapore are also called amusement arcades.

Games in the arcades are relatively clean in content. Erotic games and gambling games are missing. Some degree of violence is, however, tolerated. Unlike game software for home video game consoles and handheld video game consoles, there is no pirated game software produced for arcade machines at game centers. Game centers order software from Japan or other nations through Singapore dealers and all software has to be approved by the Films and Publication Department of the Singapore government. Games with excessive sex and violence are banned. Usually, in order to avoid trouble, manufacturers and importers exercise self-censorship.

If Sony has the upper hand in the home video game market and Nintendo controls the handheld video game market, then Sega is a major player in the arcade video game 
market in Singapore. Sega provides a large number of machines and their software. Other major manufacturers of arcade video game machines and software are SNK, Namco, and Capcom. Sega game software for coin-operated machines is the most expensive. Big game arcades can afford it, whereas medium-size game centers have fewer Sega games. ${ }^{9}$ SNK poses a great challenge to Sega in Singapore by offering software at very competitive prices. Most arcades in Singapore have more than 50 machines. The large ones have more than 100 machines. There are five major dealers in Singapore which sell or rent coin-operated video game machines (Singtel, 1998: 9293). The largest one is Valibel, which distributes Sega, Namco and SNK machines to many major game centers, including Funland. The most popular and largest game centers are all located in the city (the business and shopping areas in central Singapore).

Running the game centers is a profitable business. ${ }^{10}$ The number of game centers has been increasing steadily over the years. Even in the economic turmoil of 1998, 14 game centers closed and 19 opened. The business is booming and each game center has a considerable number of regular patrons, mostly students.

A standard game arcade in Singapore has about $1 / 3$ to $1 / 5$ race games. The most popular genre is the car game. In particular, Daytona (by Sega) has been the most popular race game and a must for all game arcades in Singapore for the past 3-4 years. ${ }^{11}$ Other popular game genres include fighting games (e.g., Street Fighter series, Virtua Fighter and The King of Fighters), shooting games (e.g., Virtua Cops and Time Crisis), sports games (e.g., Virtua Striker series) and dancing games (e.g., Dance Dance Revolution). The most popular arcade games in 1999 and 2000 are Virtua Striker 2, The King of Fighters 98, Daytona 2, Time Crisis, Beat Mania and Dance Dance Revolution. $^{12}$

Most players play with friends rather than by themselves. Popular games for game arcades and home video game consoles are different. For instance, role playing games (RPG) (e.g., Legend of Zelda and Final Fantasy) are extremely popular for home video game consoles, but they are rare at game arcades, because it takes a long time for the player to figure out the story. Likewise, platform games (e.g., The Super Mario 
Brothers and Sonic Blast Man) are more popular at home than at game arcades. Two types of games are particularly popular at game centers. First, games which require special machines or accessories. Second, games which can compete with others. In order to boost their business, many big game centers organize game competitions. For instance, Fun Factory organizes a game competition once a year.

Playing video games at game centers is affordable but can be costly, depending on the habit of the players. The minimum charge for each game is from 50 cents (at small game centers located outside the city) to a dollar. Some popular and high-tech games may cost more. This is not cheap when we compare it with other forms of entertainment in Singapore. For instance, a movie in Singapore costs only \$7 which provides non-stop entertainment for about two hours. Money burns at game centers. A 30-minute visit can cost more than $\$ 10$ if you are not a skillful player.

Compared to their counterparts in Hong Kong and Taiwan, game centers in Singapore are more spacious and have more large-size machines, such as skiing, fishing, speed boat race, and car race. However, they import new games a few months slower. Singapore players do not follow new games closely and they are not very demanding. Hence, game centers in Singapore change games slowly. Hong Kong and Taiwan import Japanese original versions of the games, whereas Singapore prefers waiting for the English versions. In Singapore, the ratio of English versions of games is the highest in Asia. There are some games in Japanese and a few in Mandarin, but they are less popular.

The number of video game arcades in Hong Kong and Taiwan has been decreasing since the 1990s. Many small game centers have closed down, replaced by mega game centers. However, the situation in Singapore is not the same. Following the building of new shopping malls, more game arcades are being opened. ${ }^{13}$

The game center culture is different from that in Hong Kong. In Hong Kong, small game centers have the image of being hangouts for gangsters. Some players are wild, rude and noisy. Game centers put the air conditioner and the sound of the machines at the maximum level. Fighting and police ID checks are routine. Patrons in Singapore 
are relatively quiet, well-mannered and polite. They seldom create trouble and the police do not bother the centers. The temperature and sound levels are just right. In Hong Kong, some skillful players invite challengers for their favorite games. Sometimes, the losers lose not only face but some money. For instance, Daytona is a popular game for gambling. In Singapore this behavior is very rare. It happens only once in a while at small game centers in suburban areas. In Hong Kong, players have made many unwritten but common rules among themselves. For instance, putting a token on the top of the machine is a symbol of booking for the next game. In certain games such as Street Fighter, Hong Kong players also have made some rules to make the game more fair or exciting. These practices are not found among players at game centers in Singapore. This is a barometer of the immaturity of the Singapore video game culture.

\section{Characteristics}

How can we locate the video game culture in Singapore within a larger context of the globalization of Japanese popular culture? What are its distinctive characteristics? We will examine these issues from three different angles.

Compared with other forms of Japanese popular culture in Singapore, the video game culture is quite unique. First, it came to Singapore later but made an impact earlier. Although Japanese comics, animation, TV dramas, Sanrio merchandise, and cuisine came to Singapore a long time ago, most of them did not become very popular until the 1990s. First introduced to Singapore in the mid-1980s, Japanese video games became an instant success.

Second, it has been one of the most popular forms of Japanese popular culture in Singapore. Only comics and animation can match its popularity. Since the introduction of the home video game system in the mid-1980s, the video game culture has been growing strongly and it has shown no signs of decline. According to our January 1998 survey, about $60 \%$ of males and $39 \%$ of females between 14 and 26 play video games on a regular basis. Our March 1999 survey shows even a larger figure-64\% of young 
Singaporeans between 13 and 29 play video games on a regular basis. In terms of gender, $86 \%$ of males and $55 \%$ of females play video games on a regular basis.

Third, video games stimulate the consumption of other forms of Japanese popular culture in Singapore. Popular video games, such as Street Fighter, The Mario Brothers, Pokemon, Digimon, Samurai Spirits, Fatal Fury, Tekken, Final Fantasy, The King of Fighters and Rock Man, give rise to comics, films, animation, CDs, VCDs, merchandise and other spin-offs.

Fourth, playing video games is mainly a children's and young men's culture in Singapore. Most players are primary or secondary school students. For other forms of Japanese popular culture, the main patrons are teenagers and those in their early twenties, mostly high school and university students.

Fifth, video games have no competitors of its kind. In comics, animation, TV dramas, music, food, fashion, and merchandise, Japanese popular culture is competing with its Western, Asian and local counterparts. However, the entire video game market in Singapore, like that in the rest of the world, is monopolized by the Japanese.

The popularity of video games follows economic growth. It cannot be popular in nations in which few people have either televisions or constant contact with electronic and computer products. The diffusion rate of television in Singapore is almost $100 \%$. This provides a good foundation for the video game market. Playing video games is a popular indoor entertainment. It is perfect for a small nation like Singapore where outdoor activities are few and the outside temperature is high. The number of game players has increased steadily over the years. The economic turmoil in 1998 had little impact on this growing video game market. Sales of home video game consoles and handheld games are doing very well. The business of game arcades is also good and the number of game arcades is increasing. There are about 43 video game dealers in Singapore which sell consoles and software. The largest dealer is Game Tokyo (now renamed as Pretty in Tokyo) which operates 10 shops (Singtel, 1998: 1188-1189).

Popular video games (e.g., Street Fighter 2 and The Mario Brothers) and handheld electronic games (e.g., such as Tamagotchi and Digimon) have become a part of the 
history of youth culture in Singapore. For instance, due to the popularity of Street Fighter 2, Ryû, the hero of the game, became an object of worship and imitation. Kids learned to leap and punched the way Ryû does. "Ha do ken," a phrase uttered by Ryû when he delivers a fireball, was picked up by children to mean punching ( $\mathrm{Ng}, 1998$ : 26). ${ }^{14}$ Capcom, the designer of game, even organized a Street Fighter 2 open tournament at Takashimaya (Capcom 1998: 11). ${ }^{15}$

By putting the Singapore video game market in the world context, we must admit that Singapore is still a developing and not a very mature market. The popularization of Japanese video games in Singapore is only on a par with other major cities in Southeast Asia, such as Kuala Lumpur, Bangkok and Manila. In terms of the percentage of players and consoles per capita, and the degree of knowledge and enthusiasm, Singapore lags behind leading video game markets in the world, such as Japan, the US, Taiwan and Hong Kong. The home video game system is considered a household necessity like television and rice cooker in these leading markets, but in Singapore, less than half of the families own one. Even among the young generations, many of them have never owned a home video game system. According to our survey conducted in January 1998, although most of young Singaporeans have played video games at game arcades or a friend's house, only $57 \%$ have owned a home video game console.

Many Japanese hardware and software companies have set up offices in Hong Kong, Taiwan and the US, but very few of them have an office in Singapore. ${ }^{16}$ Konami has a branch in Taiwan to create Chinese game software. A number of Taiwanese companies have acquired the license from Japanese software makers to make Chinese versions of Japanese video games. Taiwanese and Hong Kong software companies have begun to write and sell games for Japanese makers. All of these activities are missing in Singapore. Although Singapore has many software companies, none creates video game software.

The attitudes of the players in Singapore are also different from their counterparts in the leading markets. Players in the leading markets take the games more seriously. They form game clubs, visit game fairs, read game magazines, queue up to buy new 
games, and burn the midnight oil to find ways to win. In Japan, there are many books and magazines on video games. The US, Taiwan, Hong Kong, Kuala Lumpur and Bangkok have their own video game magazines. Singapore players are in need of a true fan (otaku) spirit. A typical Singapore player does not read game magazines. Singapore has not produced a single game magazine of its own, nor even a video game corner in any newspaper or magazine. There are three Chinese game magazines sold in Singapore-Game Players (\$10) and Game Weekly (\$4) from Hong Kong and Style Game Magazine (\$14) from Taiwan. There are several game magazines from the US but they are more expensive (\$13-30). Few sell more than 1,000 copies per issue in Singapore. ${ }^{17}$ Local players are completely ignorant of new trends.

The Singapore mass media and press are not supportive of this video game culture. Although video games are popular among children, they are not included in children's TV programs. In Hong Kong and Taiwan, video games are a must in children's programs. For instance, the Asian channel in Hong Kong broadcasts news about video games and organizes competitions in its children's programs on a regular basis. In Singapore, none of its local magazines or newspapers has a game corner. In Hong Kong, popular weeklies such as East Touch and Easyfinder and leading newspapers such as Apply Daily and Oriental Daily have a video game corner. In Hong Kong, the mass media and press report stories about game shows and game competitions. Although many game competitors have been organized in Singapore by Japanese companies, local reporters show no interest in these events. ${ }^{18}$

Singaporeans tend to play by themselves. According to our January 1998 survey, $40 \%$ of the respondents said they play the game alone. Usually they play on their home game console or play handheld electronic games by themselves but play coin-operated machines with their friends. Unlike their US or Japanese counterparts, they seldom play with their family members. Our March 1999 survey shows that only 17\% of our respondents play with family members regularly. The same survey shows that $62 \%$ of the players usually play at their own home, $25 \%$ usually play at game centers, and $13 \%$ usually play at their friend's place. 
Chart 1: The Favorite Place for Singapore Game Players

The Favorite Place for Singapore Game Players

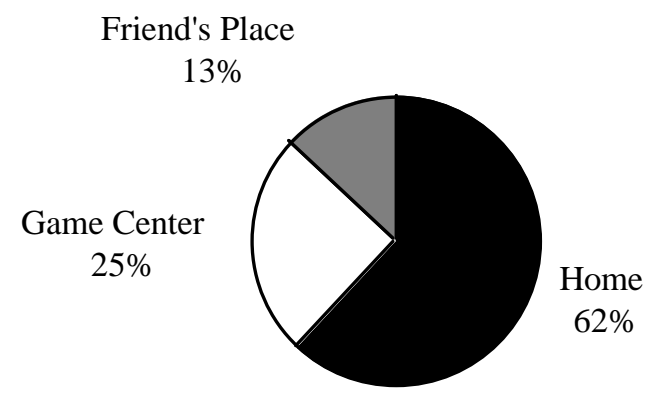

Singapore players do not spend much time on video games. According to our March 1999 survey, 84\% of players spend less than ten hours a month. Only 8\% play more than 30 hours a month or more than one hour a day.

Chart 2: Time Spent on Video Games Each Month among Singapore Players

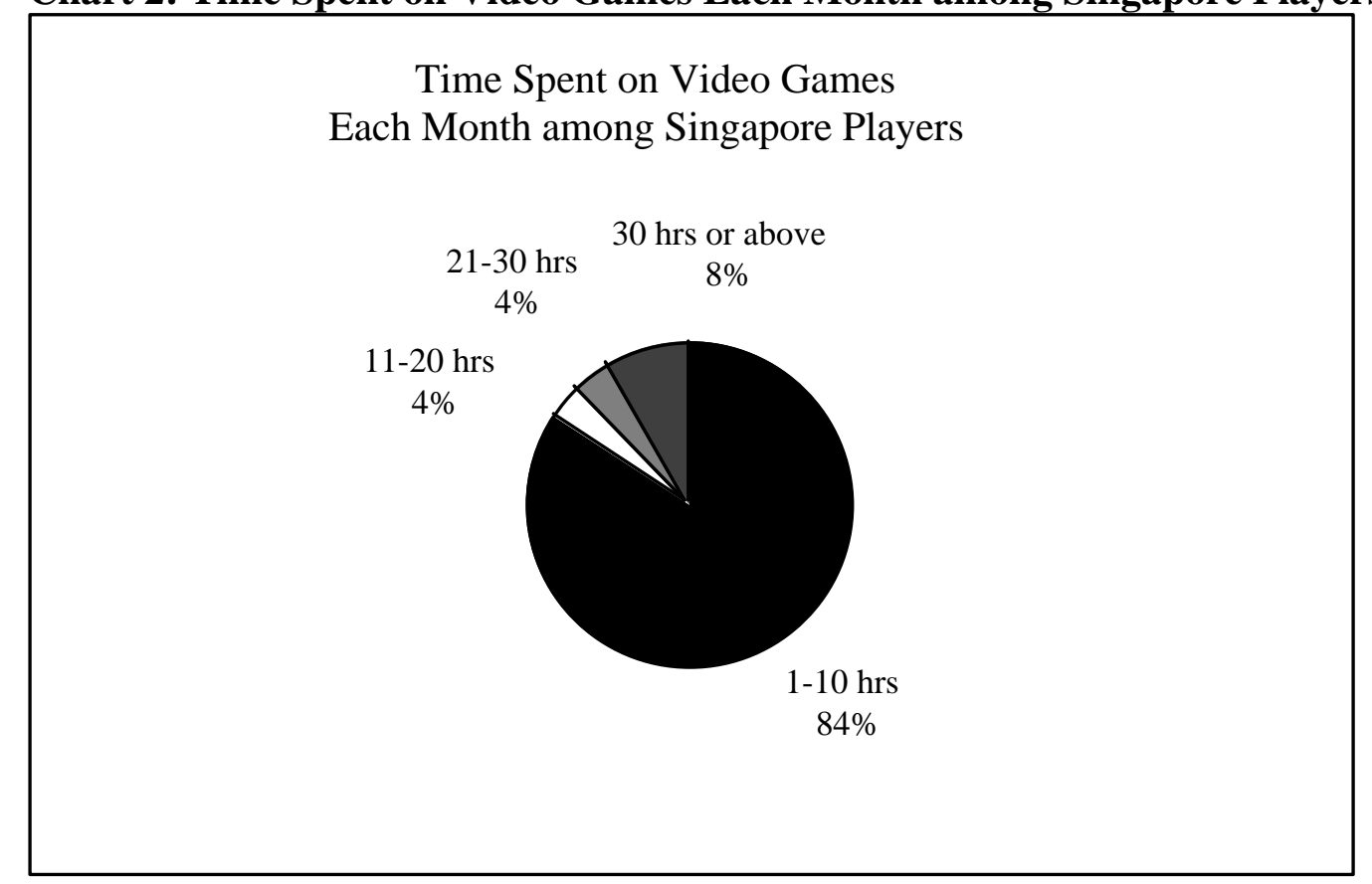


Singapore players buy games without much serious thought. They are influenced by the price, suggestions by shop keepers or friends, and their impressions of the games they play at game centers. Most of them buy pirated software because it is much cheaper. An average Singaporean owns about 15-30 pieces of software for one home game console. This is little bit less than their counterparts in Hong Kong or Taiwan, but more than those of the Japanese or British, who buy expensive original game software. ${ }^{19}$

Singapore players are slow to follow new developments. Although the video game has entered the age of 128-bit technology, most local players are still satisfied with the 32-bit Sony Playstation and Sega Saturn and even the 16-bit Super Nintendo Entertainment System or Sega Genesis. Many still play games made in the 1980s and early 1990s. Some game shops still carry SNES and Sega Genesis. New and limited versions of games are not well received in the Singapore market, because most players are not knowledgeable and care less about recent trends. Game dealers in Singapore import new games slowly, usually six months to one year later than in Taiwan or Hong Kong. The number of games imported is fewer. Singapore players prefer waiting for the English version of the games. Games in Japanese are few and less popular. For instance, Graduation is a popular game in Japan, but has not been well received in Singapore because it contains too many Japanese dialogues. Games such as World's First Soccer and Oda Nobunaga's den are popular in Japan, Taiwan and Hong Kong, buy they are virtually unavailable in Singapore because they do not have English versions.

In recent months, we have even seen a puzzling reverse phenomenon in Singapore that some low-tech pirated video game consoles made in China which can play 10-60 built-in antiquated games, such as The Mario Brothers, Bomberman, and Galaxian, are being sold at $\$ 20-70$. The most popular one is Gun Boy $(\$ 29)$, which includes platform games, shooting games and RPG games.

Singapore players do not care about Japanese history, culture and language. To them, a video game is an entertainment without a national boundary. The Japaneseness in video games does not mean much to them. In Taiwan or Hong Kong, many video 
game players are interested in Japanese history, culture and language, because they want to understand more about their favorite games. For instance, after playing J-League's and Nobunaga's games, they look for information about J-League and the life of Oda Nobunaga. Taiwanese and Hong Kong game players are also interested in knowing some Japanese. Almost all game magazines have a corner on the Japanese language. Singapore players do not bother. To them, a game is just a game, and not a springboard for knowing about Japan.

Singapore players spend little money on video games. Our March 1999 survey indicates that $88 \%$ of Singapore players spend less than $\$ 20$ a month, $10 \%$ spend $\$ 20-50$ and $2 \%$ spend more than $\$ 50$. This is possible because most players buy pirated software and do not buy game magazines.

\section{Chart 3: Monthly Spending on Video Games among Singapore Players}

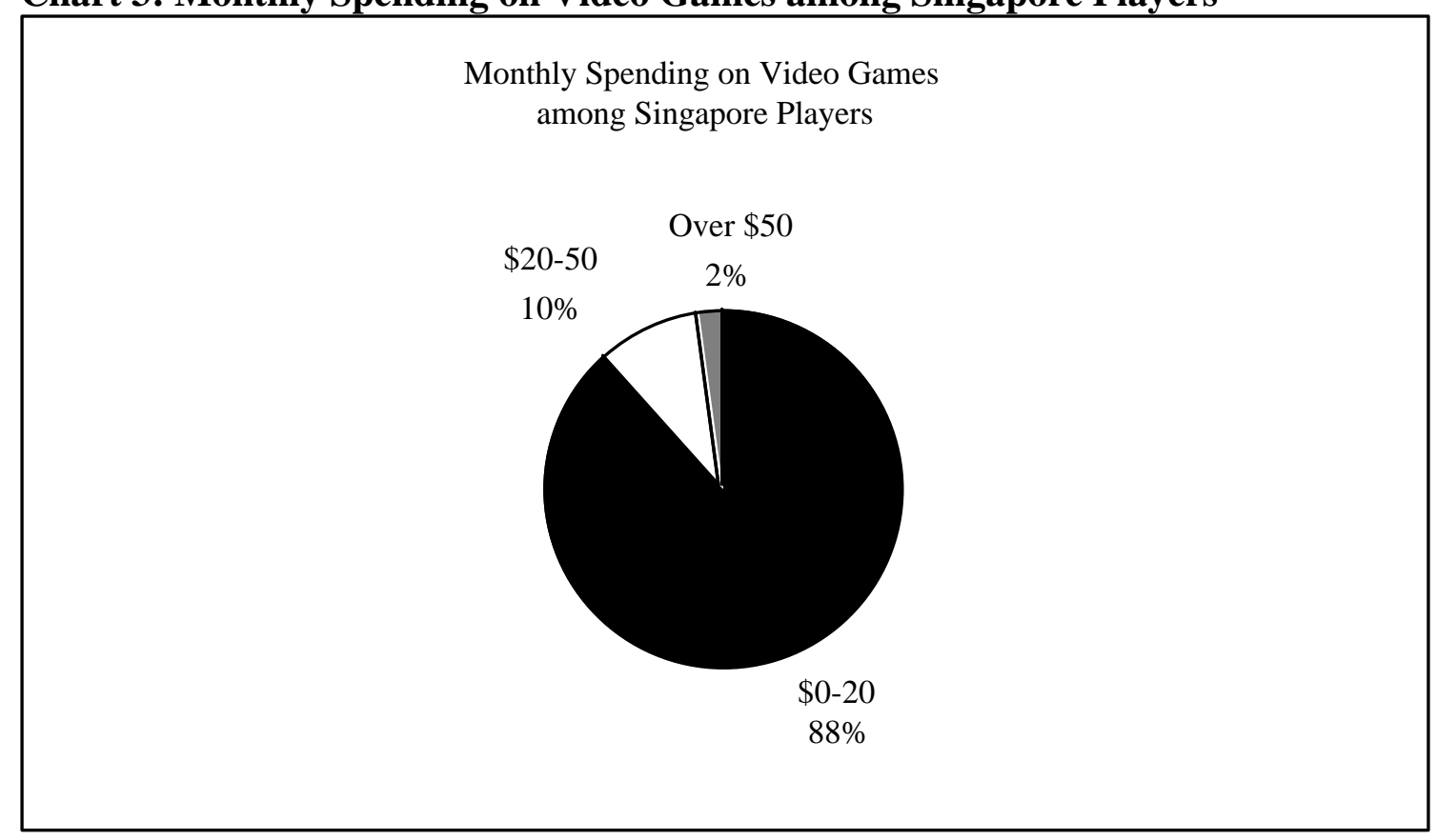

Singapore is an importer of pirated games (Suzuki, 1997: 43-50). All nations have some regulations against pirated software, but whether they are forceful in exercising them or not is another matter. There is very little pirated software in Japan. Japanese consumers are willing to pay for the original game software. ${ }^{20}$ Taiwan, China and Malaysia are major manufacturing and distribution centers of pirated games. Hong 
Kong and Singapore are major importers of pirated games. In Singapore, many players buy and many game shops sell pirated software exclusively. According to our March 1999 survey, $28 \%$ of Singapore players buy only pirated software. As a matter of fact, it is much easier to buy pirated than original software. Many game titles are only available in pirated software. Game shops also suggest that their customers buy pirated software because of its higher profit margin. Piracy popularizes video games in the short term, but hurts the video game industry and culture in the long term. Singapore is one such example.

Singapore has a good reputation for protecting copyrights and patent. The piracy rate here is said to be the lowest in Asia. ${ }^{21}$ It is said that video game makers only loses about $\$ 7$ million a year in Singapore, compared with about $\$ 1,400$ million in China, \$109 million in Taiwan and \$102 million in Hong Kong. However, the situation in Singapore is worsening and pirated software is easily available.

The Singapore government has tried to crack down on pirated software but to no avail. In Sim Lim Square alone, there are 25 unauthorized dealers selling pirated Sony or Sega CD software. Policemen (usually plainclothes) and Sony or Wywy personnel come to check almost every month. Every now and then some people are caught and fined, but the business goes on. A large raid took place on 22 January 1998. The Singapore government and the Software Publisher Association (SPA) sent their staff to seize more than 2,000 pirated CDs at five different shops in Sim Lim Square (Lianhe zaobao, 1998: 8). SPA has chosen Singapore as the center of its anti-piracy activities. It launched a series of anti-piracy campaigns and even set up an anti-piracy hotline in Singapore.

Game shops have smart ways to beat the system. Inspectors can hardly find any pirated CDs in their shops, because they are stored in hidden compartments or in locations outside the shops. Usually they show the game folders to the customers for them to choose and get the pirated CDs for them from other locations. Some shops sell pirated CDs only at night or on certain days. Some employ ex-convicts to operate the shops and to take the legal responsibility when caught. Shops form an intelligence 
network and inform each other on things such as police raids and susceptible persons. Besides Sim Lim Square, there are many temporary shops and makeshift stalls over all Singapore selling pirated video game software.

The censorship of video games in Singapore is not as strict as that of movies, comics, and TV programs. The Singapore government has the right to ban video games which contain excessive sex and violence. For example, Mortal Combat, a game of blood and torture, has been banned. This game has the same fate in Hong Kong. Even some US congressmen wanted to ban it (Herz, 1997: 183-195). However, the Board of Film Censors in Singapore does not vet every video game. Its control is indirect. It allows the import and distribution of any video game as long as game importers make a declaration that the games neither depict excessive sex and violence, nor glorify crime, gangs and discrimination (Singapore 1997, 1997: 291). The Board of Film Censors only screens certain video games when it receives complaints from teachers or parents. If the games are found problematic, the importer will be punished severely. Hence, game importers and distributors in Singapore exercise self censorship and do not import games with excessive sex and violence. Mahjong and card games were popular in Japan, Taiwan and Hong Kong, but they were not introduced to Singapore because of their sexual content. When the player wins, the sexy girl on the screen will take off her clothes piece by piece. Sega Saturn has a number of X-rated games. Their pirated CDs can be found in Singapore. Sony Playstation has not developed any X-rated game. Its office in Singapore even introduces games (e.g., Gun Barl) which can be played by the entire family to promote family values. On Father's Day 1999, Song Playstation organized a video game tournament for father-son teams to compete at Funan Centre. The Singapore government only regulates and selectively screens the authentic games. Since most software is pirated, it does not go through the Board of Film Censors. Hence, censorship has a larger impact on coin-operated machines which use original software than the home game consoles or handheld games which use pirated software. Banned or controversial games are usually popular underground. 


\section{Concluding Remarks}

Many Americans see Japanese video game as a form of cultural imperialism (Herz, 1997; Sheff, 1993). However, it seems that Japanese video game is largely a technology without a strong ideology and cultural identity. Unlike J-pop, TV dramas or movies which are made for the home market, the Japanese video game industry targets the global market (though some games such as Oda Nobunaga's den and The Legend of the Three Kingdoms are made for Japanese and Asian markets). Japanese video games have more universal appeal and contain less Japanese flavor than other forms of Japanese popular culture (Iwabuchi, 1999: 179-183). Hence, Japanese video games should be viewed as a commodity or consumer technology rather than a cultural product. Singapore game players like Japanese video games because of their universal appeal and not the Japanese flavor. Due to the universality of Japanese video games, localization is difficult. Unlike sushi, karaoke or instant ramen (noodle) which can be re-made to suit local flavor, Japanese video games cannot be reprogrammed. Nevertheless, some degree of localization of Japanese video games can still be found in Singapore due to political (e.g., censorship which makes the games relatively 'clean'), economic (e.g., cheaper to buy pirated software) and cultural (preference for games in English) reasons.

To conclude, Japanese video game culture has taken root in Singapore. It is one of the most popular forms of Japanese popular culture in Singapore. Its role in youth culture, consumption and entertainment will continue to grow. However, it still has a long way to go. The market is small and immature, and it is flooded with pirated software. The players do not have the otaku spirit. They are not well-informed and are slow to follow new developments. Game manufacturers do not see Singapore as an important market and few have set up an office. The boom of Japanese video games in Singapore is somewhat isolated. The mass media and the press do not promote video games and video games do not stimulate players' interest in Japan. If there are no improvements in these areas, video games may continue to be a popular form of entertainment but a considerable increase in their influence on Singapore society, culture, education and language is unlikely. 


\section{Acknowledgements}

The author would like to express his gratitude to the Sumitomo Foundation for providing a research project for a project on the impact of Japanese popular culture in 1998. He also wishes to thank Kenneth Sim, Tam Wai-lok and the reviewers for their useful comments, and to the Public Entertainment Licensing Unit at Singapore Police Force, Asia Project Department at the Sony Playstation Office in Singapore, Bandai Singapore Office, and Fun Factory for providing information.

\section{Notes}

1. The popularity of video games in the 1980 s should not be exaggerated. The number of players was small and many families did not have a second TV set for video games. According to our January 1998 survey conducted on 100 young Singaporeans between 14 and 26, even in the heyday of NES, only one out of twenty five of our respondents owned an NES. NES was much popular in Japan and the US (See Kinder, 1991: 89-93).

2. Sony is famous for applying a strategy called 'global localization' (i.e., global companies should be sensitive to local preference) to relatively immature market. This applies to Sony's business strategy in Singapore and Southeast Asia. Roland Robertson calls this Japanese business strategy "Glocalization."

3. Microsoft is developing a powerful game console, X-Box, to compete with the Japanese, but the critics are not optimistic of its chances.

4. Bandai officially introduced Tamagotchi in Singapore in April 1997 and set the price at $\$ 25$. However, parallel importers already brought it in by early 1997 and sold it at $\$ 40$.

5. Bandai has an office in Singapore which imports Digimon to distributors (e.g., Rubberband) and retailers (e.g., Seven Eleven). However, many shops also import Digimon from Japan, Hong Kong or Taiwan through their own connections. These parallel importers introduce new versions much faster than the authorized dealers, but they charge higher prices. 
6. This information is provided by $\mathrm{L}$. C. $\mathrm{Ng}$, the Licensing Officer in the Public Entertainment Licensing Unit at Singapore Police Force, in a letter dated 10 December 1998.

7. According to the manager of Fun Factory during an interview in January 1999, each of its centers has only about 300 customers on weekdays, but has about 3,000 customers on weekends and holidays.

8. Photo-sticker is one of the hottest fads in Singapore. The photo-sticker machine looks like a stand-up arcade game. By inserting $\$ 4$, one can make a set of photostickers. It is extremely popular and profitable. According to a spokesman for Namco Wonderland at Bugis Junction (now closed down), about $40 \%$ of its revenue of the game arcade came from photo-sticker machines. Although many game centers have these machines, most receive only rents from Japanese video game companies. In 1999, a new sticker machine, rakugaki, also came to Singapore. Rakugaki has extra functions such as inserting a message.

9. Popular Sega arcade games such as Virtua Striker cost about $\$ 10,000$. The most expensive game is Daytona 2, which costs $\$ 250,000$ because the machine and the software plate are inseparable. Games by Capcom and SNK are very affordable. Most are in the range of $\$ 1,500-\$ 3,000$.

10. For instance, the profit for each center of Fun Factory is about $\$ 100,000$ to $\$ 220,000$ a month. The impact of the economic downturn was mild in 1998 and early 1999.

11. It seems that the fad is over. Wywy canceled its annual Daytona tournament in 1998 because of the poor response. Daytona 2 has been on the Singapore market since late 1998 but it cannot bring back its old glory.

12. Dance Dance Revolution (DDR) is the hottest arcade game in late 1999 and 2000 (Lianhe zaobao, 1999: 3).

13. The latest trend is the mushrooming of small-size cyber video game centers and LAN game centers where customers buy time to play computer game with others 
interactively. These games are designed by Japanese and Americans (Lianhe zaobao, 2000: 45)

14. The Street Fighter series is perhaps the most popular fighting game ever in Singapore, serving as the model for other fighting games. Street Fighter 2 can be played by SNES, 3DO, Playstation, and Saga Saturn. Street Fighter 2 was one the most popular arcade games and now Street Fighter 3 is very popular in Singapore. In early 2000, the fastfood chain, A \& W, used the CD-rom of Street Fighter Zero 2 to promote its set menu.

15. Capcom has an office in Hong Kong but not in Singapore. However, it comes to organize promotions frequently. For example, it held a "Capcom Carnival 97 Singapore" on 27-28 September 1997 at the Takashimaya Shopping Center. An open tournament for Street Fighter 3 and a championship tournament for Street Fighter between the champions from Malaysia and Singapore were the main attractions. More than 8,000 Singaporeans participated in this carnival.

16. Sony Playstation, Bandai, Konami and SNK have an office in Singapore, but it seems that only Sony Playstation office is active. The Bandai office covers mainly Digimon and merchandise, and Konami and SNK offices are small liaison offices.

17. In Hong Kong, popular game magazines sell many times more. For instance, Game Plus (\$10 HKD) sells about 50,000 copies per issue and Game Players (\$35 HKD) about 30,000-40,000 copies per issue. Most Hong Kong game players are readers of game magazines. However, the circulation of Game Players in Singapore is only 800 copies per issue. These data are provided by the chief editor of Game Players in January 1999.

18. Occasionally, Singapore television and newspapers report on video games. For instance, City Beat, a program about youth culture in Singapore, introduced a large game center, Hollywood Slam, in one of its episodes. Newspapers carried some stories about the fad of Tamagotchi, Digimon and Dance Dance Revolution. 
19. On the average, a British player buys only eight games for each game console (Hayes, 1995: 31).

20. The price of original software in Japan is much cheaper than in Taiwan, Hong Kong or Singapore. The second-hand market for original software is also very large. The Japanese government is very forceful in suppressing piracy.

22. For a dissenting view, see The Sunday Times, 1998: 2. According to Dominic

Nathan, US copyright owners representing software and publishing industries claimed that they lost US \$124.9 million in 1997 because of copyright violations in Singapore.

\section{References}

Capcom

$1998 \quad C F C$, first issue. Hong Kong, February, p. 11.

Hayes, Michael and Stuart Disney

1995 Games War: Video Games, A Business Review. London: Bowerdean.

Herz, J.C

1997 Joystick Nation: How Video games Ate Our Quarters, Won Our Hearts, Iwabuchi, Koichi and Rewired Our Minds. Boston: Little Brown and Co.

1998 "Return to Japan: Japan in Asian Audiovisual markets," in Kosaku Yoshino, ed., Consuming Ethnicity and Nationalism. Honolulu: University of Hawai'i Press.

Kinder, Marsha

1991 Playing With Power in Movies, Television and Video Games. Berkeley \& Los Angeles: University of California Press.

Kowloon Club, Newsletter,

1999 February, p. 6.

Lianhe Zaobao

199820 December

199913 September, p. 3.

20004 November, p. 45.

Lianhe wanbao

19981 December, p. 11.

Monopolies and Mergers Commission (ed.)

1995 Video Games: A Report on the Supply of Video Games in the UK. London: H.M.S.O.

$\mathrm{Ng}$ Wai-Ming, Benjamin

1999 "Japanese Animation in Singapore: History, Characteristics and Comparison". In Japanese Studies Department (ed.) Japan-Southeast Asia Relations: International Conference 1999 Proceeding. March, 
Singapore: Department of Japanese Studies, National University of Singapore, pp. 234-246.

2000 "A Comparative Study of Japanese Comics in Southeast Asia and East Asia". International Journal of Comic Art, May, 2 (1), pp. 44-56.

2000 "Japanese Comics in Singapore". Asian Culture, June Vol. 24, pp. 1-14.

$\mathrm{Ng}$ Wui Seng

1998 Japanese Video Games in Singapore: A Study of Hardware, Software and Players. Honors Thesis. Department of Japanese Studies, National University of Singapore 1997/1998.

Robertson, Roland

1995 "Glocalization: Time, Space and Homogeneity-Heterogeneity," in Roland Robertson, Mile Featherstone, and Scott Lash, eds., Global Modernities. London: Thousand Oaks.

Sheff, David

1993 Game Over: How Nintendo Zapped an American Industry, Captured Your Dollars and Enslaved Your Children. New York: Random House.

1997 Singapore: Ministry of Information and the Arts.

Singapore Telecom

1998 Buying Guide, Singapore Yellow Pages July 1998/1999 Singapore Telecom.

1999 Buying Guide, Singapore Yellow Pages July 1999/2000. Singapore Telecom.

Sony

1999 Gamers' Action Times. Singapore: Sony.

Suzuki Hodo

1997 Kaizoku sofuto no hon (Book of Pirated Software). Tokyo: Sansai Books.

The Straits Times

19979 April, p. 8.

The Sunday Times

1998 Dominic Nathan, "US firms want Singapore blacklisted for rising copyright violations". 8 March, p. 2.

International Herald Tribune

1997 Sheryl WuDunn“An Unlikely Story, A Runaway Success: Virtual Pet Beeps, Bothers-and Sells,” 8 September, p. 6. 